\title{
BIOSSÓLIDO NA COMPOSIÇÃO DE SUBSTRATOS PARA PRODUÇÃO DE MUDAS DE DUAS ESPÉCIES FLORESTAIS UTILIZADAS NA ARBORIZAÇÃO URBANA
}

\section{BIOSOLID IN THE SUBSTRATES COMPOSITION FOR THE PRODUCTION OF SEEDLINGS FOR URBAN FOREST}

\author{
Juçara Garcia Ribeiro ${ }^{1}$, Paulo Sérgio dos Santos Leles², Aline Cássia da Fonseca³ \\ Thasso José Silva e Sousa ${ }^{4}$, João Elves da Silva Santana ${ }^{5}$
}

\section{RESUMO}

O lodo de esgoto é um produto resultante do tratamento de águas residuárias das Estações de Tratamento de Esgoto (ETE) que depois de estabilizado é denominado biossólido. Este componente constitui fonte de matéria orgânica e de nutrientes, apresentando potencial para a produção de mudas florestais, além de reduzir os impactos ambientais ocasionados pela disposição inadequada desse resíduo. Este trabalho objetivou avaliar o potencial do biossólido como componente de substrato para a produção de mudas de Handroanthus impetiginosus e Libidibia ferrea para fins de arborização urbana. Foram testadas diferentes proporções volumétricas de biossólido (BIO) misturado em subsolo argiloso (SA) e tratamento controle constituído por esterco bovino (EB) misturado em subsolo argiloso, constituindo as seguintes formulações: $\mathrm{T} 1=40 \% \mathrm{~EB}+60 \% \mathrm{SA} ; \mathrm{T} 2=20 \% \mathrm{BIO}+80 \% \mathrm{SA} ; \mathrm{T} 3=40 \% \mathrm{BIO}+$ $60 \% \mathrm{SA} ; \mathrm{T} 4=80 \% \mathrm{BIO}+20 \% \mathrm{SA}$. Dados de altura e diâmetro de coleto foram coletados, trimestralmente, até 12 meses após o transplantio das mudas para as latas com capacidade volumétrica de 18 litros. As mudas das duas espécies não apresentaram diferenças significativas entre os tratamentos utilizados, sendo possível empregar tanto o esterco bovino quanto as dosagens de biossólido avaliadas no presente estudo.

Palavras-chave: Ipê-roxo; Pau-ferro; Lodo de esgoto.

\section{ABSTRACT}

The sewage sludge is a product of the wastewater treatment that is developed in the wastewater treatment plants that after stabilization is named biosolid. This component is a source of organic matter and nutrients presenting potential for forest seedlings production and also reducing the impacts in the environment occasioned by the inadequate disposal of this residue. This study aimed to evaluate the potential of using biosolid as a substrate component for the production of Handroanthus impetiginosus and Libidibia ferrea seedlings for urban forest. Different volumetric proportions of biosolid (BIO) mixed to clay subsoil were tested and a control treatment of cattle manure (CM) mixed to clay subsoil (CS), constituting the following treatments: $\mathrm{T} 1=40 \% \mathrm{CM}+60 \% \mathrm{CS} ; \mathrm{T} 2=20 \% \mathrm{BIO}+80 \% \mathrm{CS} ; \mathrm{T} 3=40 \% \mathrm{BIO}+$ $60 \% \mathrm{CS} ; \mathrm{T} 4=80 \% \mathrm{BIO}+20 \% \mathrm{CS}$. Height and collar diameter were collected, quarterly, up to 12 months after transplanting of the seedlings for the 18 liter volumetric cans. Seedlings of two species did not present significant difference between proposed treatments therefore, being possible to use whether cattle manure or biosolid in any of the proportions presented in this study.

Keywords: pink trumpet tree; Brazilian ironwood; Sewage sludge.

Recebido em 19.08.2017 e aceito em 04.05.2018

1 Engenheira Florestal. Mestranda do Programa de Pós-Graduação em Ciências Ambientais e Florestais da UFRRJ. Rio de Seropédica/RJ. Email: jucara.garcia.ribeiro@gmail.com

2 Engenheiro Florestal. Dr. Professor Associado III do Departamento de Silvicultura da UFRRJ. Seropédica/RJ. Email: pleles@ufrrj.br

3 Engenheira Florestal. Mestranda do Programa de Pós Graduação em Ciências Florestais pela UNESP. Botucatu/SP. Email: aline cfonseca@hotmail.com

4 Técnico em Agropecuária. Graduando em Engenharia Florestal pela UFRRJ. Seropédica/RJ. Email: thassojss@hotmail.com

5 Engenheiro Florestal. Mestrando do Programa de Pós-Graduação em Ciências Ambientais e Florestais da UFRRJ. Rio de Seropédica/RJ. Email: joaoelvissantana@gmail.com 


\section{INTRODUÇÃO}

Com mais de $70 \%$ da população brasileira vivendo no perímetro urbano, a arborização urbana assume papel de vital importância garantindo melhorias da qualidade de vida e inúmeros benefícios ocasionados pela presença de plantas nas vias públicas (FARIA et al., 2013). Entre os benefícios, encontra-se a melhoria microclimática, amenização acústica, atuação como filtros de partículas que poluem o ar, proteção do solo e sobrevivência da avifauna (BLUM; BORGO; SAMPAIO, 2008; MARTINI, BIONDI, 2015; MARTINI et al., 2017).

Dentre as espécies florestais comumente empregadas na arborização urbana encontram-se as espécies Handroanthus impetiginosus (Mart. ex DC) Mattos (ipê-roxo) e Libidibia ferrea (Mart. ex Tul.) Queiroz (pau-ferro). A primeira conhecida como ipê-roxo é uma espécie pertencente à família Bignoniaceae, seus exemplares podem atingir de 8 a $20 \mathrm{~m}$ de altura. Apresenta crescimento moderado a rápido, perda das folhas nas épocas mais secas do ano e sistema radicular pivotante. Sua floração é abundante, tomando toda a copa das árvores, o que a torna uma árvore com características adequadas para a ornamentação da arborização urbana (CARVALHO, 2003).

Libidibia ferrea, conhecida como pau-ferro, pertence à família Fabaceae, subfamília Caesalpinioideae. Segundo Carvalho (2003), é uma espécie secundária inicial presente em toda a região Nordeste do Brasil, até parte do Sudeste. Esta espécie apresenta características ornamentais, devido principalmente às características do seu tronco liso, cinzento e com malhas claras e aspecto escamante bem característico. A copa é bem verticalizada, constituída por folhas compostas por folíolos verde-escuros, proporcionando boa sombra.

Um dos aspectos importantes para o sucesso da arborização urbana é a qualidade das mudas, segundo Oliveira et al. (2013) entre outras características, as mudas devem apresentar altura da parte aérea de no mínimo de 2,0 metros. Por isso, devem ser produzidas em recipientes com capacidade volumétrica superior a 15 litros, a fim de proporcionar condições para que o crescimento do sistema radicular seja compatível com o da parte aérea. Assim, o volume de substrato é relativamente alto, quando comparado com mudas produzidas para outros fins. Para produzir mudas de arborização urbana, normalmente utiliza-se terra de subsolo para proporcionar consistência e estrutura e material orgânico para oferecer nutrientes e porosidade ao substrato (RODRIGUES et al., 2002).

O esterco bovino é uma fonte de matéria orgânica bastante utilizada em substratos para produção de mudas de espécies nativas (CALDEIRA et al. 2008). Segundo Alonso (2013), o mesmo é considerado o principal limitante da produção na região metropolitana do Rio de Janeiro, onde estão localizados a maior parte dos viveiros do estado. Este fato ocorre em virtude da atividade pecuária na região metropolitana do estado ser reduzida, dificultando a 
disponibilidade de esterco em quantidade e qualidade. Assim, é necessário buscar novas alternativas de fonte de matéria orgânica para produção de mudas, que seja mais disponível e de baixo custo, devido o consumo relativamente alto para produção das mudas de arborização urbana.

Entre os materiais potenciais para utilização como substrato para produção de mudas, tem-se o biossólido de lodo de esgoto, que normalmente é disposto em aterros sanitários. O biossólido é um resíduo sólido obtido após o tratamento de água residuária proveniente das Estações de Tratamento de Esgoto (BONINI; ALVES; MONTANARI, 2015) e seco em leitos de secagem, assemelhando visualmente a composto orgânico ou a esterco bovino curtido. Estudos de Abreu et al. (2017a) e Cabreira et al. (2017b) mostram que este material tem potencial como substrato para produção de mudas de espécies arbóreas da Mata Atlântica, uma vez que o mesmo constitui fonte de matéria orgânica e de nutrientes para as plantas (SCHEER et al., 2012; ABREU et al., 2017b; CABREIRA et al., 2017a), além de atuar como condicionador de solos e fertilizante para recuperação de áreas degradadas, adubo orgânico na agricultura e fins florestais (SAMPAIO et al., 2012; CALDEIRA et al., 2014; LIMA FILHO, 2015; ABREU et al., 2017b).

Um potencial do biossólido de lodo de esgoto é utilizá-lo como componente de substrato para produção de mudas para arborização urbana, contudo os estudos são escassos. As mudas da arborização urbana por serem produzidas em recipientes acima de 15 litros precisam de volume relativamente alto de fonte de matéria orgânica e o biossólido necessita de um destino mais adequado. Segundo Guerrini et al. (2017) com o aumento de tratamento de esgoto doméstico nos últimos anos, o biossólido é gerado em grandes quantidades em diversas áreas metropolitanas brasileiras e seu destino, como uso em arborização urbana, contribui para reduzir problemas ambientais associados a sua utilização. Outro fator importante é que o biossólido é gerado nas cidades e as mudas de arborização são plantadas na área urbana, com isso diminui o preço de transporte das mudas do viveiro até o local de plantio. Contudo, o biossólido pode apresentar diversos poluentes como metais pesados, além de organismos patogênicos prejudiciais ao homem, diante do exposto, surgiu a resolução no 375/2006 do Conselho Nacional do Meio Ambiente - CONAMA (BRASIL, 2006) restringindo o uso na agricultura, principalmente na produção de tubérculos, tornando esse componente um potencial para produção de mudas de arborização urbana, em virtude dos menores riscos de contaminação.

Este trabalho objetivou avaliar o uso de diferentes proporções de biossólido como fonte de matéria orgânica na composição de substrato para a produção de mudas de Handroanthus impetiginosus e Libidibia ferrea para arborização urbana. 


\section{MATERIAL E MÉTODOS}

O estudo foi desenvolvido no Viveiro Florestal no Instituto de Florestas da Universidade Federal Rural do Rio de Janeiro, localizado no município de Seropédica, RJ.

O experimento teve início em novembro de 2014 com a realização da semeadura e finalizado em março de 2016. Segundo dados obtidos do Instituto Nacional de Meteorologia (INMET) da estação meteorológica de Seropédica - RJ, a temperatura média da região no período da realização do experimento foi de $24,2{ }^{\circ} \mathrm{C}$, sendo fevereiro o mês mais quente, com temperatura média de $27,4 \stackrel{\circ}{ } \mathrm{C}$ e junho o mês com a mais baixa temperatura no período da realização do experimento, com média de $21,7^{\circ} \mathrm{C}$.

As espécies utilizadas foram Handroanthus impetiginosus e Libidibia ferrea, cada espécie constituiu um experimento. Inicialmente, as mudas foram produzidas em tubetes plásticos de $280 \mathrm{~cm}^{3}$, utilizando $80 \%$ de biossólido (lodo de esgoto tratado e estabilizado) e $20 \%$ de fibra de coco. Os recipientes ficaram alocados ao sol, com a realização, em média, de irrigação uma vez ao dia, sofrendo variações dependendo das condições climáticas e das necessidades da planta, através de observações visuais. Quando as mudas estavam com altura média em torno de $25 \mathrm{~cm}$ foram transplantadas para as latas.

Cinco meses após a realização da semeadura (março de 2015), foram selecionadas 24 mudas de cada espécie, que apresentaram altura e diâmetro mais uniforme, totalizando 48 mudas. As mudas de ipê-roxo apresentavam altura da parte aérea de $20 \mathrm{~cm}$ e diâmetro de coleto de $4 \mathrm{~mm}$ e as de pau-ferro $30 \mathrm{~cm}$ e $4 \mathrm{~mm}$, respectivamente, medidos com o auxilio de régua graduada e paquímetro digital, para obter as dimensões no tempo zero. Estas avaliações também foram realizadas aos 3, 6, 9 e 12 meses após transplantio. As mudas selecionadas foram transplantadas para latas com capacidade volumétrica de 18 litros e com perfuração no fundo. As latas foram cheias com o auxílio de pá, até aproximadamente $2 \mathrm{~cm}$ da borda, certificando-se que os mesmos estavam com boa compactação a fim de evitar espaços sem preenchimento. Assim, foram utilizados cerca de 15 litros de substratos para cada recipiente.

O delineamento experimental utilizado foi inteiramente casualizado, constituído por quatro tratamentos, com seis repetições, que totalizaram 24 plantas para cada espécie. Os tratamentos foram:

a) T1 - testemunha, substrato formado por composto de esterco bovino e subsolo argiloso na proporção volumétrica de 40-60\%, respectivamente

b) T2 - substrato formado por biossólido e subsolo argiloso na proporção volumétrica de $20-80 \%$;

c) T3 - substrato formado por biossólido e subsolo argiloso na proporção volumétrica de 40-60\%; 
d) T4 - substrato formado por biossólido e subsolo argiloso na proporção volumétrica de $80-20 \%$, respectivamente.

Quinze dias após o enchimento dos recipientes e transplantio das mudas, foram retiradas amostras dos substratos e enviadas para laboratório de fertilidade de solos. Os resultados da análise química encontram-se na Tabela 1.

Tabela 1. Análise química dos quatro substratos utilizados para o crescimento de mudas de duas espécies usadas para arborização urbana, aos 15 dias após transplante para as latas de 18 litros

Table 1. Chemical analysis of the four substrates used for the growth of seedlings of two species used for urban forest at 15 days after transplantation for 18 liter cans

\begin{tabular}{|c|c|c|c|c|c|c|c|c|c|c|}
\hline \multirow{2}{*}{ Substrato } & \multirow{2}{*}{$\begin{array}{c}\mathrm{pH} \\
\left(\mathrm{H}_{2} \mathrm{O}\right)\end{array}$} & \multirow{2}{*}{$\begin{array}{c}\mathrm{N} \\
\text { dag kg-1 }\end{array}$} & $P$ & $\mathrm{~K}^{+}$ & $\mathrm{Ca}^{2+}$ & $\mathrm{Mg}^{2+}$ & $\mathrm{Al}^{3+}$ & $\mathrm{T}$ & V & $\mathrm{m}$ \\
\hline & & & \multicolumn{2}{|c|}{----mg dm³---- } & \multicolumn{4}{|c|}{------- $\mathrm{Cmol}_{\mathrm{c}} \mathrm{dm}^{-3}$} & \multicolumn{2}{|c|}{---------\%------ } \\
\hline $40: 60^{*}$ & 5,5 & 0,23 & 190 & 550 & 6,3 & 2,8 & 0,0 & 10,7 & 87,0 & 0,0 \\
\hline $20: 80^{* *}$ & 5,1 & 0,17 & 240 & 30 & 6,5 & 0,85 & 0,1 & 11,3 & 63,2 & 1,3 \\
\hline $40: 60^{* *}$ & 5,0 & 0,36 & 420 & 82 & 13,8 & 0,90 & 0,1 & 12,5 & 60,0 & 1,2 \\
\hline $80: 20^{* *}$ & 4,9 & 0,38 & 550 & 95 & 15,2 & 0,84 & 0,1 & 16,1 & 51,6 & 1,0 \\
\hline
\end{tabular}

${ }^{*}$ Proporções volumétricas, em sequência de esterco bovino e subsolo argiloso. **Proporções volumétricas, em sequência de biossólido e subsolo argiloso.

pH em água; N (N total): Digestão sulfúrica - Destilação Kjeldhal; P e K: extrator Mehlich-1; Ca, Mg e Al: extrator de KCl 1 mol/L; $\mathrm{T}$ - Capacidade de troca catiônica a pH 7,0; V= Índice de saturação por bases; $m$ = Índice de saturação por alumínio.

O biossólido utilizado foi proveniente da estação de tratamento de esgoto (ETE) Alegria, no Rio de Janeiro, bairro Caju e foi disponibilizado pela Companhia Estadual de Águas e Esgoto do Rio de Janeiro (CEDAE). O esgoto tratado pela ETE Alegria é derivado de áreas urbanas domiciliares e comerciais, não contendo resíduos industriais. A estação conta com sistema de tratamento secundário de lodos ativados e adensamento de lodo secundário através de centrífugas. Após o processo de desaguamento em centrífugas, os lodos passam por processo de desidratação permanecendo por aproximadamente 90 dias em leitos de secagem a pleno sol, atingindo umidade por volta de $30 \%$. O resultado da análise química do biossólido utilizado encontra-se na Tabela 2.

Tabela 2. Análise química do biossólido (amostra base seca) em \%, utilizado na composição de substratos

Table 2. Chemical analysis of biosolids (dry base sample) in \%, used in the composition of substrates

\begin{tabular}{|c|c|c|c|c|c|c|c|}
\hline${ }^{* 1} \mathrm{pH}$ & ${ }^{*} \mathrm{~N}$ & ${ }^{*} 2 \mathrm{P}$ & ${ }^{*}{ }^{2} \mathrm{~K}^{+}$ & ${ }^{*} \mathrm{Ca}^{2+}$ & ${ }^{*} \mathrm{Mg}^{2+}$ & ${ }^{*} \mathrm{Al}^{3+}$ & ${ }^{*}{ }^{5} \mathrm{M} . \mathrm{O}$. \\
\hline 5,5 & 1,94 & 0,81 & 0,19 & 1,59 & 0,19 & 2,72 & 35,3 \\
\hline
\end{tabular}

${ }^{\text {"1 }} \mathrm{pH}$ em água: Potenciometria; ${ }^{2} \mathrm{~N}$ : Kjeldahl; ${ }^{* 3} \mathrm{P}$ : Método Colorimétrico; ${ }^{*} \mathrm{~K}$ : Fotometria de chama; ${ }^{5} \mathrm{Ca}, \mathrm{Mg}$ e Al: Espectrometria de absorção atômica; "6Matéria orgânica (M.O): Gravimétrico.

O esterco bovino utilizado foi retirado do curral de gado de leite da Estação de Pesquisa Agropecuária do Estado do Rio de Janeiro (PESAGRO), unidade Seropédica, onde a alimentação dos animais é a base de capim elefante e ração, complementado com pastejo em 
áreas com predomínio de capim colonião. Após retirar do curral o esterco foi deixado em repouso por aproximadamente 60 dias, para estabilização.

O subsolo utilizado é proveniente de camada de $40-200 \mathrm{~cm}$ de profundidade e foi coletado em Seropédica, RJ. Todos os componentes de substratos foram peneirados em peneira com furos de aproximadamente $2 \mathrm{~cm}$. A análise química do subsolo argiloso encontrase na Tabela 3.

Tabela 3. Análise química de subsolo argiloso utilizado para composição de substratos para produção de mudas de duas espécies usadas na arborização urbana

Table 3. Chemical analysis of clayey subsoil used for substrate composition to produce seedlings of two species used in urban forest

\begin{tabular}{cccccccccc}
\hline $\begin{array}{c}\mathrm{pH} \\
\left(\mathrm{H}_{2} \mathrm{O}\right)\end{array}$ & $\mathrm{P}$ & $\mathrm{K}$ & $\mathrm{Ca}$ & $\mathrm{Mg}$ & $\begin{array}{c}\mathrm{Al} \\
-\end{array} \mathrm{Cm}^{-1}-\mathrm{H}+\mathrm{Al}$ & $\mathrm{T}$ & $\mathrm{V}$ & $\mathrm{M}$ \\
\hline 4,3 & 11 & 8 & 0,8 & 0,6 & 2,6 & 6,4 & 7,84 & 18 & 64,36
\end{tabular}

* pH em água - Relação 1:2,5; P e K extrator Mehlich-1; Ca, Mg e Al extrator de $\mathrm{KCl}$ 1,0 mol/L; $\mathrm{H}+\mathrm{Al}$ extrator de acetato de cálcio; $V=$ índice de saturação por bases; $m=$ índice de saturação por alumínio; $T=$ capacidade de troca catiônica a pH = 7,0.

Ao longo do experimento foi realizado capina manual para retirada de plantas espontâneas evitando a competição com as espécies de interesse.

Em setembro de 2015 (seis meses após o transplantio), com uso de um trado, foram retiradas amostras de substratos de todas as latas e constituídas as amostras compostas por substratos, sendo misturadas as amostras das duas espécies, as quais foram enviadas para laboratório de solos, para determinação de características químicas. No sexto mês as mudas foram tutoradas com bambu e barbante e realizadas podas de formação.

Os dados obtidos através das medições foram processados, analisados e para cada espécie e tratamento foram elaborados gráficos de crescimento em altura e diâmetro de coleto, nas quatro avaliações realizadas. Os dados de cada espécie e época de avaliação foram submetidos ao teste de Barttlet para testar a homogeneidade das variâncias e ao teste de Lilliefors para homogeneidade dos dados, constatando não haver necessidade de transformação. Em seguida, os dados foram submetidos a análise de variância $(P \geq 0,95)$. Para todas análises estatística utilizou-se o software Sistemas de Análises Estatísticas e Genéticas (SAEG).

\section{RESULTADOS E DISCUSSÃO}

Para as duas espécies estudadas, não houve diferenças significativas $(P \geq 0,95)$ nos valores médios de altura e diâmetro de coleto em nenhuma das avaliações realizadas (Tabela 4). 
Tabela 4. Valores de quadrado médio da altura da parte aérea e do diâmetro do coleto de Handroanthus impetiginosus e Libidibia ferrea em quatro épocas após transplantio

Table 4. Mean square values of shoot height and collar diameter of Handroanthus impetiginosus and Libidibia ferrea in four seasons after transplanting

\begin{tabular}{|c|c|c|c|c|c|c|c|c|c|}
\hline \multirow[t]{2}{*}{$\mathrm{FV}$} & \multirow[t]{2}{*}{ GL } & \multicolumn{2}{|c|}{----- 3 meses ----- } & \multicolumn{2}{|c|}{------ 6 meses --- } & \multicolumn{2}{|c|}{----- 9 meses ----- } & \multicolumn{2}{|c|}{----- 12 meses ---- } \\
\hline & & Altura & Diâmetro & Altura & Diâmetro & Altura & Diâmetro & Altura & Diâmetro \\
\hline \multicolumn{10}{|c|}{ Handroanthus impetiginosus } \\
\hline Tratam. & 3 & 41,2 & 1,77 & 139,6 & 5,95 & 1433,8 & 8,93 & 2464,8 & 5,93 \\
\hline Resíduo & 20 & 76,9 & 2,69 & 195,3 & 5,65 & 790,2 & 8,55 & 885,4 & 16,9 \\
\hline C. variação ( & & 27,1 & 25,5 & 27,3 & 27,1 & 26,6 & 22,6 & 24,5 & 24,6 \\
\hline \multicolumn{10}{|c|}{ Libidibia ferrea } \\
\hline Trat & 3 & 221,7 & 2,87 & 2651,4 & 5,11 & 2345,3 & 4,34 & 2146,0 & 24,37 \\
\hline Resíduo & 20 & 185,0 & 3,64 & 1284,0 & 5,52 & 1995,8 & 4,70 & 1909,3 & 5,21 \\
\hline C. variação ( & (\%) & 22,2 & 19,52 & 27,13 & 16,03 & 22,08 & 11,91 & 19,24 & 10,35 \\
\hline
\end{tabular}

Os valores médios de crescimento em altura e diâmetro do coleto de Handroanthus impetiginosus e Libidibia férrea podem ser observados na Figura 1.

Embora não tenha sido observada diferença estatística entre os tratamentos, esperavase que as mudas produzidas em maiores proporções de biossólido apresentariam melhores resultados, devido ao maior teor de matéria orgânica do substrato, assim como verificado para espécies florestais nativas utilizando biossólido nos trabalhos realizados por Fonseca (2015), Lima Filho (2015) e Cabreira et al. (2017b). Fonseca (2015) trabalhando com produção de mudas de Paubrasilia echinata Lam. (pau-brasil), Dalbergia nigra (Vell.) Allemão ex Benth. (jacarandá-da-bahia) e Cariniana legalis (Mart.) Kuntze (jequitibá-rosa) em sacos plásticos, observou que as mudas das duas primeiras espécies apresentaram melhores crescimentos nos tratamentos com maiores doses de biossólido. Cariniana legalis não apresentou diferença significativa no crescimento das mudas, sendo indicado pelo autor a proporção de $80 \%$ de biossólido para produção das espécies utilizadas. Cabreira et al. (2017b) produzindo mudas de Peltophorobium dubim (Spreng.) Taub. (farinha-seca), Lafoensia pacari A.St.-Hil (dedaleiro) e Ceiba speciosa (A. St.-Hil.) Ravenna (paineira-rosa), usando mesmo recipiente de Fonseca (2015), observaram que as mudas produzidas com maiores proporções de biossólido apresentaram menor tempo para formação das mudas, em comparação ao substrato utilizando-se esterco bovino, evidenciando o potencial de redução do tempo das mudas com o uso de biossólido, sendo indicada a quantidade entre 40 a $80 \%$ de biossólido na composição do substrato. 


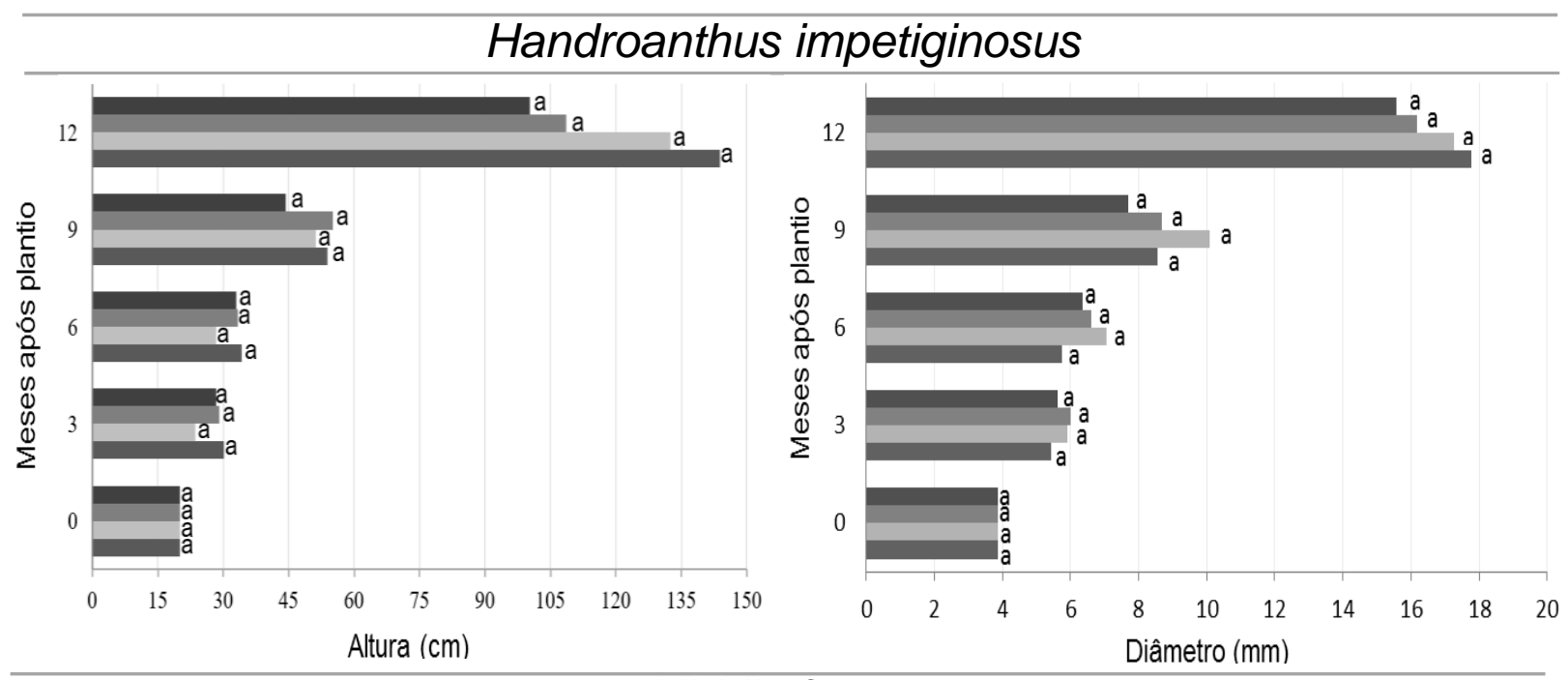

\section{Libidia ferrea}
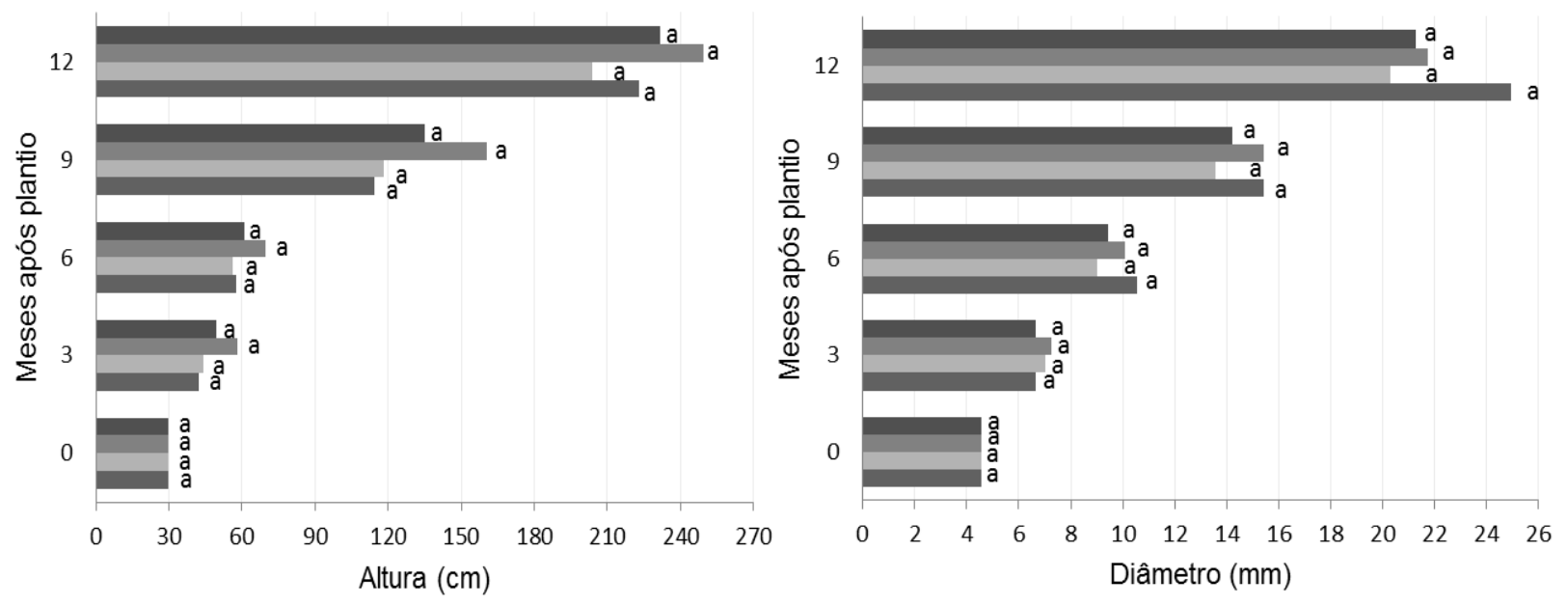

$80: 20^{* *} \square 40: 60 * *-20: 80^{* *} \square 40: 60 *$

*Proporções volumétricas, em sequência de esterco e subsolo argiloso. **Proporções volumétricas, em sequência de biossólido e subsolo argiloso.

Figura 1. Altura de mudas e diâmetro do coleto de Handroanthus impetiginosus e Libidibia ferrea produzidas em quatro substratos, em diferentes épocas após o transplantio, para recipientes de 18 litros. Para cada idade, médias seguidas de mesma letra, não diferem entre si, pelo teste de Tukey $(P \geq 0,95)$

Figure 1. Height and collar diameter of seedlings of Handroanthus impetiginosus and Libidibia ferrea, produced in four substrates, at different times after transplanting, for 18 liter cans. For each age, means followed by the same letter do not differ from each other, by the Tukey test $(P \geq 0.95)$

Lima Filho (2015) avaliou os efeitos de doses crescentes de biossólido no crescimento e nutrição da Ceiba speciosa, utilizando terra da camada de $0-40 \mathrm{~cm}$ de um Latossolo Vermelho Amarelo Distrófico. O experimento foi realizado utilizando vasos de 18 litros, sendo os tratamentos formados pela testemunha (constituído apenas por solo), dosagens de 5\%, $9 \%$, $18 \%$ e $37 \%$ de biossólido. O autor observou que independente da dose de biossólido 
empregado, o crescimento médio das plantas foi mais acelerado, quando comparado ao tratamento testemunha. A dose ideal para maior crescimento das plantas de paineira ficou em torno de $25 \%$ de biossólido, constituindo o substrato do vaso.

É importante salientar que mudas para arborização urbana, segundo Oliveira et al. (2013), devem apresentar altura mínima de 2,0 metros. Assim, ao observar os gráficos da Figura 1, constata-se que apenas as mudas de Libidibia ferrea apresentaram altura mínima para serem utilizadas na arborização até o período de análise.

Provavelmente, devido ao tempo relativamente longo que as mudas permaneceram no viveiro, além da própria demanda nutricional das espécies, não houve diferença significativa entre os tratamentos. Este fato pode ser inferido pela Tabela 5, onde, de modo geral, os níveis de nutrientes são considerados bons para as espécies florestais, aos 6 meses após o transplantio das mudas para as latas de 18 litros.

Tabela 5. Análise química dos quatro substratos utilizados para o crescimento de mudas de duas espécies usadas para arborização urbana, aos 6 meses após transplante para as latas de 18 litros

Table 5. Chemical analysis of the four substrates used for the growth of seedlings of two species used for urban forest at 6 months after transplantation for 18 liter cans

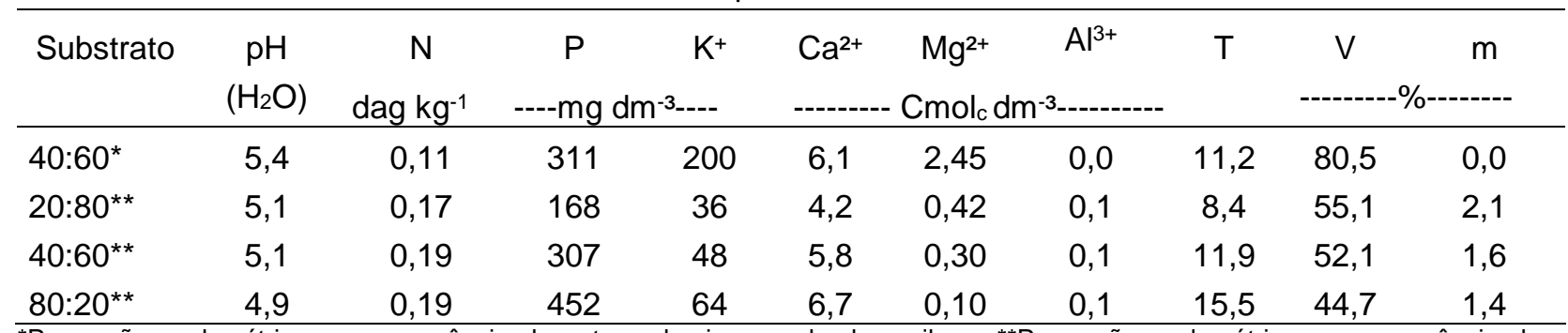

*Proporções volumétricas, em sequência de esterco bovino e subsolo argiloso. ${ }^{* *}$ Proporções volumétricas, em sequência de biossólido e subsolo argiloso.

pH em água; N (N total): Digestão sulfúrica - Destilação Kjeldhal; P e K: extrator Mehlich-1; Ca, Mg e Al: extrator de KCl 1 mol/L; $\mathrm{T}$ - Capacidade de troca catiônica a $\mathrm{pH} 7,0 ; \mathrm{V}=$ Índice de saturação por bases; $m$ = Índice de saturação por alumínio.

As amostras de solos de todos os substratos apresentaram indicadores de $\mathrm{pH}$ não adequados, pois segundo Carneiro (1995) o pH ideal que permite boa absorção de nutrientes pelas plantas está na faixa de 5,5 a 6,5. Lima Filho (2015) observou que aos seis meses após o transplante das mudas de Ceiba speciosa, o tratamento com 9\% de biossólido apresentou $\mathrm{pH}$, em média, significativamente superior $(\mathrm{P}>0,95)$ ao tratamento que não houve aplicação de biossólido. Observou também que com as doses crescentes exponencialmente de biossólido não foram constatadas alterações significativas de $\mathrm{pH}$.

Aos seis meses após o transplante, os teores de nitrogênio aparentemente foram maiores nos substratos compostos por biossólido, mesmo nas menores dosagens utilizadas, quando comparado com o tratamento constituído por esterco bovino. Isto ocorreu devido ao biossólido apresentar o nitrogênio como o macronutriente em maior abundância (CALDEIRA et al., 2012, ABREU et al., 2017b). Lima filho (2015) constatou não haver diferenças significativas 
nos teores de nitrogênio e magnésio, seis meses após o plantio das mudas de Ceiba speciosa nas doses crescentes de biossólido usadas. Segundo este último autor, a possível explicação para a falta de diferenças é decorrente das características do solo e da demanda nutricional da espécie, tendo parte dos elementos lixiviada com a água percolada pelos vasos ou absorvida pelas plantas.

Aparentemente, os baixos teores de potássio encontrados nos tratamentos que levaram o biossólido em sua composição, quando comparado com o tratamento testemunha, constituído por esterco bovino, baseado nas informações de Abreu et al. (2017a), é devido este elemento ser altamente solúvel em água, sendo perdido com efluentes líquidos durante o processo de tratamento de esgoto, ocasionando assim, alterações nos teores de material orgânico.

Visivelmente os teores de $\mathrm{Al}^{+3}$ dos substratos aos seis meses após o plantio, indicaram que mesmo utilizando dosagens mais elevadas de biossólido, não ocorreu aumento do mesmo. A utilização de biossólido normalmente aumenta os teores de matéria orgânica e segundo Freire et al. (2013) a sua presença pode promover a complexação do alumínio, formando quelatos e reduzindo seu efeito tóxico, em consequência, os teores de $\mathrm{Al}^{+3}$ presentes no solo diminuem. Lima Filho (2015) observou que a menor dosagem de biossólido resultou na redução drástica da concentração de $\mathrm{Al}^{+3}$, indicando o potencial que este composto possui na complexação deste elemento.

A capacidade de troca catiônica (CTC) aparentemente apresentou aumento de acordo com o acréscimo da quantidade de biossólido utilizada para cada tratamento. Segundo Zandonadi et al. (2014) a matéria orgânica que é responsável por fornecer nutrientes, também apresenta cargas de superfície que aumentam a capacidade de troca catiônica (CTC) do solo, fazendo com que regule a disponibilidade de diversos nutrientes, principalmente os micronutrientes e influencia também na atividade de elementos potencialmente fitotóxicos como $\mathrm{Al}^{3+}$ e $\mathrm{Mn}^{2+}$.

\section{CONCLUSÕES}

Até a idade avaliada e nas condições em que foi realizado o experimento, para a produção de mudas de Handroanthus impetiginosus e Libidibia ferrea destinadas à arborização urbana pode-se utilizar tanto o esterco bovino, quanto as proporções de biossólido aplicadas. 


\section{REFERÊNCIAS}

ABREU, A. H. M.; LELES, P. S. S.; ALONSO, J. M.; ABEL, E. L. S.; OLIVEIRA, R. R. Characterization of sewages ludge generated in Rio de Janeiro, Brazil, and perspectives for agricultural recycling. Semina: Ciências Agrárias, Londrina, v. 38, n. 4, p. 2433-2448, 2017b.

ABREU, A. H. M.; MARZOLA, L. B.; MELO, L. A.; LELES, P. S. S.; ABEL, E. L. S.; ALONSO, J. $M$. Urban solid wast in the production of Lafoensia pacari seedlings. Revista Brasileira de Engenharia Agrícola e Ambiental, Campina Grande, v. 21, n. 2, p. 83-87, 2017a.

ALONSO, J. M. Análise dos Viveiros e da Legislação Brasileira sobre Sementes e Mudas Florestais Nativas no Estado do Rio de Janeiro. 2013. 89 f. Dissertação (Mestrado em Ciências Ambientais e Florestais) - Universidade Federal Rural do Rio de Janeiro, Seropédica, 2013.

BRASIL. Ministério do Meio Ambiente. Conselho Nacional do Meio Ambiente. Resolução CONAMA. Resolução no 375/2006. Define critérios e procedimentos para o uso agrícola de lodos de esgoto gerados em estações de tratamento de esgoto sanitário e seus produtos derivados. Diário Oficial da República Federativa do Brasil, Brasília, n. 167, p. 141-146, 30 ago 2006.

BONINI, C. S. B.; ALVES, M. C.; MONTANARI, R.; Recuperação da estrutura de um Latossolo vermelho degradado utilizando lodo de esgoto. Revista Brasileira de Ciências Agrárias, Recife, v. 10, n. 1, p. 34-42, 2015.

BLUM, C. T.; BORGO, M.; SAMPAIO, A. C. F. Espécies exóticas invasoras na arborização de vias públicas de Maringá-PR. Revista da Sociedade Brasileira de Arborização Urbana, Piracicaba, v. 3, n. 2, p. 78-97, 2008.

CABREIRA, G. V.; LELES, P. S. S.; ALONSO, J. M.; ABREU, A. H. M.; SANTOS, G. R.; LOPES, N. F. Biossólido como componente de substrato para produção de mudas florestais. Floresta, Curitiba, v. 47, n. 2, p 161-170, 2017b.

CABREIRA, G. V.; LELES, P. S. S.; ARAÚJO, E. J. G.; SILVA, E. V.; LISBOA, A. C.; LOPES, L. N. Produção de mudas de Schinus terebinthifolius utilizando biossólido como substrato em diferentes recipientes e fertilizantes. Scientia Agrária, Curitiba, v. 18, n. 2, p. 30-42, 2017a.

CALDEIRA, M. V. W.; DELARMELINA, W. M.; LUBE, S. G.; GOMES, D. R.; GONÇALVES, E. O.; ALVES, A. F. Biossólido na composição de substrato para a produção de mudas de Tectona grandis. Floresta, Curitiba, v. 42, n. 1, p. 77-84, 2012.

CALDEIRA, M. V. W.; FAVALESSA, M.; GONÇALVES, E. O.; DELARMELINA, W. M.; SANTOS, F. E. V.; VIEIRA, M. Lodo de Esgoto Como Componente de Substrato para produção de mudas de Acacia Mangium Wild. Pesquisa Agropecuária Tropical, Goiânia, v. 5, n. 1, p. 34-43, 2014.

CALDEIRA, M. V. W.; ROSA, G. N.; FENILLT, T. A. B.; HARBS, R. M. P. Composto orgânico na produção de mudas de aroeira vermelha. Scientia Agrária, Curitiba, v. 9, n. 1, p. 27-33, 2008.

CARNEIRO, J. G. A. Produção e controle de qualidade de mudas florestais. Curitiba: UFPR-FUPEF/Campos: UNEF, 1995, 451p. 
CARVALHO, P. E. R. Espécies florestais brasileiras. Colombo: EMBRAPA/CNPF. 2003. v. 1. $1039 \mathrm{p}$.

FARIA, D. C.; DUARTE, J. M. A.; PINTO, D. M.; ALMEIDA, F. S. Arborização urbana no município de Três Rios - RJ: Espécies utilizadas e a percepção de seus benefícios pela população. Revista da Sociedade Brasileira de Arborização Urbana, Piracicaba, v. 8, n. 2, p. 58-67, 2013.

FONSECA, A. C. Biossólido na composição de substratos para produção de mudas de espécies florestais vulneráveis a extinção. 2015. 17 f. Monografia (Engenharia Florestal) Universidade Federal Rural do Rio de Janeiro, Seropédica, 2015.

FREIRE, L. R.; BALIEIRO, F. C.; ZONTA, E.; ANJOS, L. H. C.; PEREIRA, M. G.; LIMA, E.; GUERRA, J. G. M.; FERREIRA, M. B. C.; LEAL, M. A. A.; CAMPOS, D. V. B.; POLIDORO, J. C. Manual de calagem e adubação do Estado do Rio de Janeiro. Brasília: EMBRAPA; Seropédica: UFRRJ, 2013. 430 p.

GUERRINI, I. A.; CROCE, C. G. G.; BUENO, O. C.; JACON, P. R. P.; NOGUEIRA, T. A. R.; FERNANDES, D. M.; GANGA, A.; CAPRA, F. Composted sewage sludge and steel mill slag as potential amendments for urban soils involved in afforestation programs. Urban Forestry e Urban Greening. Amsterdam, v. 22, p. 93-104, 2017.

LIMA FILHO, P. Biossólido na restauração florestal: produção de mudas e adubação de plantio. 2015. 100 f. Dissertação (Mestrado em Ciências Florestais e Ambientais) Universidade Federal Rural do Rio de Janeiro, Seropédica, 2015.

MARTINI, A.; BIONDI, D. Microclima e conforto térmico de um fragmento de floresta urbana em Curitiba, PR. Floresta e Ambiente, Seropédica, v. 22, n. 2, p. 182-193, 2015.

MARTINI, A.; BIONDI, D.; BATISTA, A. C.; SILVA FILHO, D. F. Análise microclimática das diferentes tipologias de floresta urbana de Curitiba. Floresta, Curitiba, v. 47, n. 2, p. 137-144, 2017.

OLIVEIRA, A. F.; PEREIRA, G. A.; PEREIRA, J. A.; CASTRO, P. M.; COELHO, S. J. Produção e doação de mudas realizadas pela Companhia Energética de Minas Gerais (Cemig) e a percepção de moradores quanto ao plantio destas em áreas urbanas. Revista da Sociedade Brasileira de Arborização Urbana, Piracicaba, v. 8, n. 4, p. 47-58, 2013.

SAMPAIO, T. F.; GUERRINI, I. A.; BACKES, C.; HELIODORO, J. C. A.; RONCHI, H. S.; TANGANELLI, K. M.; CARVALHO, N. C.; OLIVEIRA, F. C. Lodo de esgoto na recuperação de áreas degradadas: efeito nas características físicas do solo. Revista Brasileira de Ciência do Solo, Viçosa, v. 36, n. 5, p. 1637-1645, 2012.

SCHEER, M. B.; CARNEIRO, C.; BRESSAN, O. A.; SANTOS, K. G. Crescimento e nutrição de mudas de Lafoensia pacari com lodo de esgoto. Floresta e Ambiente, Seropédica, v. 19, n. 1, p. 55-65, 2012.

RODRIGUES, C. A. G.; BEZERRA, B. C.; ISHII, I. H.; CARDOSO, E. L.; SORIANO, B. M. A.; OLIVEIRA, $H$. Arborização urbana e produção de mudas de essências florestais nativas em Corumbá, MS. Corumbá: Embrapa Pantanal, 2002. 26 p. il. (Embrapa Pantanal. Documentos, 42).

ZANDONADI, D. B.; SANTOS M. P.; MEDICI L. O.; SILVA J. Ação da matéria orgânica e suas frações sobre a fisiologia de hortaliças. Horticultura Brasileira, Brasília, v. 32, p. 14-20, 2014. 